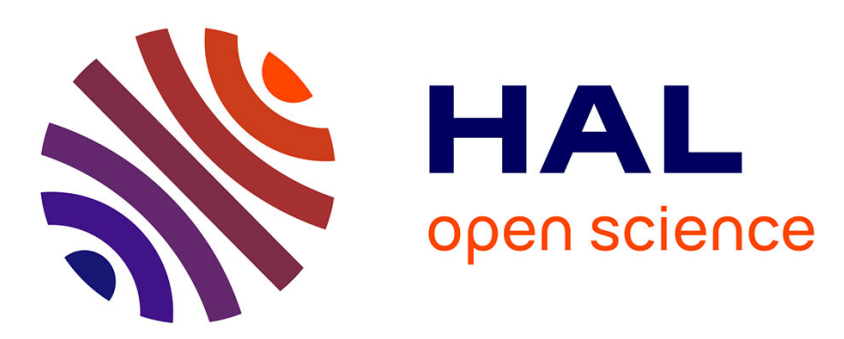

\title{
When to go with the crowd: Modelling synchronization of all-or-nothing activity transitions in grouped animals
}

\author{
Iva Dostálková, Marek Špinka
}

\section{To cite this version:}

Iva Dostálková, Marek Špinka. When to go with the crowd: Modelling synchronization of all-ornothing activity transitions in grouped animals. Journal of Theoretical Biology, 2010, 263 (4), pp.437. 10.1016/j.jtbi.2009.12.031 . hal-00578721

\section{HAL Id: hal-00578721 \\ https://hal.science/hal-00578721}

Submitted on 22 Mar 2011

HAL is a multi-disciplinary open access archive for the deposit and dissemination of scientific research documents, whether they are published or not. The documents may come from teaching and research institutions in France or abroad, or from public or private research centers.
L'archive ouverte pluridisciplinaire HAL, est destinée au dépôt et à la diffusion de documents scientifiques de niveau recherche, publiés ou non, émanant des établissements d'enseignement et de recherche français ou étrangers, des laboratoires publics ou privés. 


\section{Author's Accepted Manuscript}

When to go with the crowd: Modelling synchronization of all-or-nothing activity transitions in grouped animals

Iva Dostálková, Marek Špinka

PII: S0022-5193(10)00003-2

DOI: doi:10.1016/j.jtbi.2009.12.031

Reference: YJTBI 5821

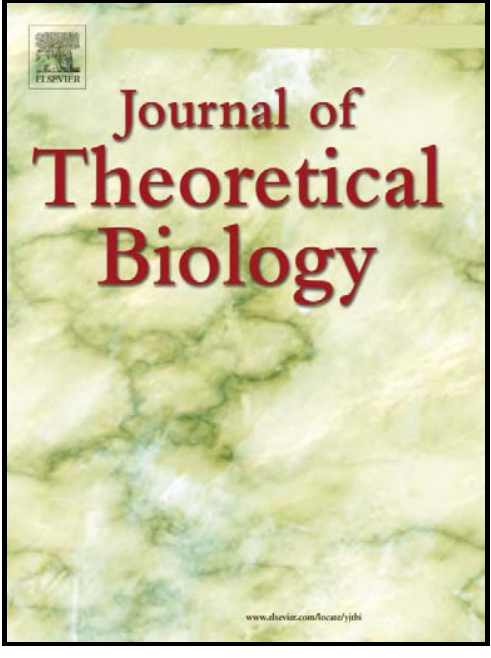

www.elsevier.com/locate/yjtbi

To appear in: Journal of Theoretical Biology

Received date: $\quad 23$ March 2009

Revised date: $\quad 8$ October 2009

Accepted date: 31 December 2009

Cite this article as: Iva Dostálková and Marek Špinka, When to go with the crowd: Modelling synchronization of all-or-nothing activity transitions in grouped animals, Journal of Theoretical Biology, doi:10.1016/j.jtbi.2009.12.031

This is a PDF file of an unedited manuscript that has been accepted for publication. As a service to our customers we are providing this early version of the manuscript. The manuscript will undergo copyediting, typesetting, and review of the resulting galley proof before it is published in its final citable form. Please note that during the production process errors may be discovered which could affect the content, and all legal disclaimers that apply to the journal pertain. 
1 When to go with the crowd: Modelling synchronization of all-or-

2 nothing activity transitions in grouped animals

3

4

5

6

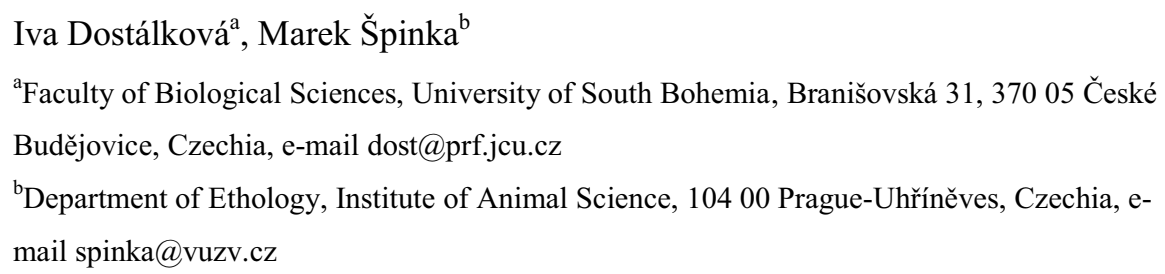

Abstract

For groups of animals to keep together, the group members have to perform switches between staying in one place and moving to another place in synchrony. However, synchronization imposes a cost on individual animals, because they have to switch from one to the other behaviour at a communal time rather than at their ideal times. Here we model this situation analytically for groups in which the ideal times vary quasi-normally and grouping benefit increases linearly with group size. Across the parameter space consisting of variation in the grouping benefit/cost ratio and variation in how costly it is to act too early and too late, the most common optimal solutions are full synchronization with the group staying together and zero synchronization with immediate dissolution of the group, if the group is too small for the given benefit/cost ratio. Partial synchronization, with animals at the tails of the distribution switching individually and the central core of the group in synchrony, occurs only at a narrow stripe of the space. Synchronization cost never causes splitting of the group into two as either zero, partial or full synchronization is always more advantageous. Stable solutions dictate lower degree of synchrony and lower net benefits than optimal solutions for a large range of the parameter values. If groups undergo repeated synchronization challenges, they stay together or quickly dissolve, unless the animals assort themselves into a smaller group with less variation in the ideal times. We conclude with arguing that synchronization cost is different from other types of grouping costs since it does not increase much with increasing 
group size. As a result, larger groups may be more stable than smaller groups. This results in the paradoxical prediction that when the grouping benefit/grouping cost ratio increases, the average group sizes might decrease, since smaller groups will be able to withstand synchronization challenges.

Keywords: group behaviour; modelling of behaviour; synchronization; group cohesion; group size

\section{INTRODUCTION}

Many animals live in stable or semi-permanent groups or at least spend shorter or longer periods of time in loose aggregations. In order to stay in proximity, group members need to coordinate when to stay in one place and when to travel. In other words, each animal has to strike a compromise between switching behavioural activities in close synchrony with others and switching the activities as close as possible to its individual ideal time (e.g,

Ruckstuhl, 1999; Meldrum and Ruckstuhl, 2009).

One example of such situation is fleeing from a predator. In many instances, the predator is noted well ahead of possible attack (either directly by the animal itself or through the alert behaviour of other flock/herd members, Sirot and Touzalin, 2009) and then an "economics of fleeing" comes into effect (Ydenberg and Dill, 1986). Initially, the costs of staying are minute (because the risk of a successful attack from large distance is negligible) and therefore lower than the costs of fleeing (including energy for the flight and lost opportunity to continue with foraging or resting). As the predator approaches, costs of staying increase at an accelerating rate (because of the climbing probability of actual attack and risk of being caught) while the costs of fleeing remain stable or increase only slightly (e.g. the animal has to run faster or for longer). At the moment when the costs of staying overcome the costs of fleeing, the animal should depart. Because many factors affecting both types of costs (such as individual ability to evade attack, current position in the group, satiation/energy reserves) vary between individuals, the ideal departure time is different for each animal. If everybody sticks to its ideal timing, animals will depart individually, the group will disintegrate and the benefits of staying and behaving together will be lost. On the other hand, should the group stay fully together and enjoy the associated benefits, everybody has to make a smaller or larger concession from its ideal timing. This dilemma is present in every situation where grouped animals can draw a benefit from switching synchronously from one behaviour 
to another such as departure from a resting place, stopping migration to rest, switching from monitoring a predator to fleeing. However, departure from a place is perhaps the most typical example and therefore the model will be described in terms of who leaves when.

Synchronization can be viewed as a consensus decision making (Conradt and Roper 2005; Conradt and List, 2009). Several theoretical and empirical studies have documented that animals can "agree" on the common solution using simple behavioural rules (Couzin et al 2005; Amé et al 2006; Martín et al 2006). If there are just two or a few disjunct possible solutions (e.g., a choice between distinct spatial goals or shelters) then simple local rules can be found that guide the group either to one of the goals, or lead to splitting of the group (Amé et al 2006, Couzin et al, 2005). Also, for groups of two animals and a continuous range of possible preferences (e.g., times of a behavioural switch), models have been developed that combine the mechanisms of coordination (e.g., communicating about inner state, simple reaction to the behaviour of the other animal) with their fitness outcomes (Rands et al., 2003; Dostálková and Špinka, 2007). Situations where there is a continuum of preferences in larger groups have been much less investigated. The only two previous studies to address these questions in terms of costs and benefits are those by Conradt and Roper. In the first paper, Conradt and Roper (2003) show that agreeing democratically on the time of the switch is usually more beneficial for the group than yielding to the time enforced by one leader animal, even if that animal has more experience or better judgement than the others. In their next study, Conradt and Roper (2007) document that for groups of three animals, agreeing on any of the three times preferred by the three group members is evolutionary stable. They then expand this analysis to larger groups and argue that also for those, any shared decision (e.g., even departing when the first animal wants to depart) is evolutionary stable. This is due to the fact that if a small subset of the group chooses to depart at another time, it will acquire some benefit from more appropriate timing (i.e. it will decrease its consensus costs), but it loses the whole benefit of acting together with the original large group. This argument holds only if the costs are small relative to grouping benefits. Conradt and Roper (2007) state this verbally but stop short of analysing the balance between consensus costs and grouping benefits quantitatively and that is where our study carries on.

The trade-off can result in four types of situations: either all animals "agree" on a common departure time (full synchronization); or each animal leaves individually (no synchronization); or something in between occurs with some individuals departing on their own while the rest leaves at a common time (partial synchronization); and lastly, animals may 
be also leaving in smaller subgroups (group splitting). Our model aims at answering three questions. First, how probable are the cases of full, partial and zero synchronization, and of group splitting? How do these probabilities depend on the benefit of being synchronized, and the costs departing too early or too late? Second, are the animals in a group able to cooperate on an optimal synchronization or are the evolutionary stable strategies for this synchronization problem suboptimal in terms of resulting net benefits? Third, the sychronisation of group departures may have an important influence on group stability and therefore stable group size. Therefore we also asked: Will repeated synchronization challenges lead to group stabilization or disintegration?

\section{MODEL I DESCRIPTION: ONE COMMON DEPARTURE VERSUS INDIVIDUAL DEPARTURES}

The detailed elaboration of the model and derivation of its results is given in Appendix A. We suppose that a group of $N$ animals is about to switch from one behaviour to another (e.g., to leave a resting place or to switch from monitoring a predator to fleeing). The animals in the group have different ideal times for the switch. These individual ideal times $t_{i}^{*}$ are symmetrically distributed around zero and constrained to the interval $\left(-t_{\max }, t_{\max }\right)$. For simplicity we assume $\left(-t_{\max }, t_{\max }\right)=(-1,1)$ (Fig. 1). For most of the animals, the individual ideal times are not far from $t^{*}=0$ while only a negligible proportion of animals prefer times immediately after $t^{*}=-1$ or just before $t^{*}=1$. In other words, the probability of the position of ideal time $t^{*}$ for a randomly chosen animal is the highest for $t^{*} \approx 0$ and it is close to zero for $t^{*}$ near $-1,1$. We assume that concrete ideal times $t^{*}$ are realizations of continous random variable "ideal time" defined by its density function $f$.

The model is setup in terms of grouping benefits and synchronization costs.

An animal that departs at a moment $t_{i}$ when a fraction $p\left(t_{i}\right)\left(0 \leq p\left(t_{i}\right) \leq 1\right)$ of the $N$-sized group depart gets a grouping benefit proportional to the number of animals in the departing group, $p\left(t_{i}\right) N Q$, where $Q$ is a constant. If an animal departs too early, i.e. at a time $t_{i}$ before its ideal time $t_{i}^{*}$, it is penalised by $-(1-\omega) L\left(t_{i}^{*}-t_{i}\right)$; if it leaves too late at $t_{i}>t_{i}^{*}$, it receives the penalty of $-\omega L\left(t_{i}-t_{i}^{*}\right)$. The parameter $\omega(0 \leq \omega \leq 1)$ describes whether it is more costly to leave prematurely $(\omega<0.5)$ or rather with a delay $(\omega>0.5)$. The product $N R$ (where $R=Q / L$ and 
$N R \geq 0$ ) is the second parameter of the model. The ratio $R=Q / L$ quantifies how important it is to be in synchrony with others, relative to the importance of departing close to the individual ideal time. The ratio $R$ is multiplied by the group size $N$ because the model assumes that the larger the group, the higher the grouping benefit. Thus the product $N R$ quantifies how much an animal can get from synchronization: the higher the parameter $N R$, the higher net potential benefit can the animals cash from being staying with the group.

The model examines how an animal should behave (i.e., when to leave) in order to accrue the highest possible net benefit, given its specific ideal time $t_{i}^{*}$ and the parameters $N R$ and $\omega$. Parameters $N R$ and $\omega$ are equal for all animals in the group. Group size $N$ is considered fixed for this model. We consider two strategies: either to depart individually at its own ideal time, or to leave together with other animals in one mass departure (Fig. 1). The solitary departure avoids any penalization for improper timing but gets no benefit from synchronization, hence its net benefit is zero. The animals participating in the mass departure benefit from synchronization (in direct proportion to the percentage of animals that leave with them), but pay for deviating from their ideal times. The cost of participating in the mass departure are higher for animals at the tails of the distribution and therefore, animals at the tails should be more inclined to use the solitary strategy while animals with their $t^{*}{ }_{i}$ closer to the centre of the distribution should rather join the mass departure (Fig. 1). We suspect that when $\omega<>0.5$, the time of mass departure $t_{D}$ will be different from zero and also the times $t_{1}$ and $t_{2}$ (breaking points where the solitary changes into the mass departure strategy and back) will be asymmetrically positioned. In the solution of the model, we are searching for such combination of times $t_{1}, t_{D}$ and $t_{2}$ that brings the highest net benefit, depending on the parameters $N R$ and $\omega$. If $t_{1}=t_{2}$, then each animal departs on its own and there is no synchronization. If $-1<t_{1}<t_{2}<1$, then some animals depart solitary and some in the mass departure, and we label this partial synchronization. And finally full synchronization occurs when $t_{1}=-1$ and $t_{2}=1$.

The net benefit function $B\left(t_{1}, t_{\mathrm{D}}, t_{2}\right)$ is the sum of the grouping benefit function $B_{G}\left(t_{1}, t_{\mathrm{D}}, t_{2}\right)$ and timing cost function $B_{C}\left(t_{1}, t_{\mathrm{D}}, t_{2}\right)$.

$B\left(t_{1}, t_{\mathrm{D}}, t_{2}\right)=B_{G}\left(t_{1}, t_{\mathrm{D}}, t_{2}\right)+B_{C}\left(t_{1}, t_{\mathrm{D}}, t_{2}\right)$, where

$B_{G}\left(t_{1}, t_{\mathrm{D}}, t_{2}\right)=N R\left(\int_{t_{1}}^{t_{2}} f(x) d x\right)^{2}$ 
$B_{C}\left(t_{1}, t_{\mathrm{D}}, t_{2}\right)=-\omega \int_{t_{1}}^{t_{D}}\left(t_{D}-x\right) f(x) d x-(1-\omega) \int_{t_{D}}^{t_{2}}\left(x-t_{D}\right) f(x) d x$

Thus, the individually departing animals do not get any grouping benefits and do not pay any timing (synchronization) costs, whereas for animals leaving in the mass departure, the net benefit equals the grouping benefit minus the synchronization costs due to un-ideal timing of the departure.

We look for two types of solutions: an optimal and a stable one. The optimal solution is such that an animal acquires, on average, the highest summary net benefit, whereas the stable solution is a solution whose net benefit cannot be improved by unilateral adoption of another solution by a small subset of the animals.

Therefore optimization procedure means to find triplets $\left[t_{1}, t_{\mathrm{D}}, t_{2}\right]$ depending on $N R$ and $\omega$ so that the value of net benefit function $B$ is maximal. Using the classical metod for maxima finding we obtain the set of maxima $\left(\frac{\partial B}{\partial t_{1}}=\frac{\partial B}{\partial t_{2}}=\frac{\partial B}{\partial t_{D}}=0\right)$ inside and on the borders of the simplex $\left\{-1 \leq t_{1} \leq t_{D} \leq t_{2} \leq 1\right\}$ that correspond to zero, partial and full behavioural synchronization.. After comparison of all possible maximal points for given parameters $N R$ and $\omega$ we obtain the point of global maximum - the optimal strategy $I=\left[t_{1}, t_{\mathrm{D}}, t_{2}\right]$.

The strategy $\mathrm{I}=\left[t_{1}, t_{\mathrm{D}}, t_{2}\right]$ is then stable, if the mixed net benefit is locally maximal. We consider an alternative strategy $\mathrm{J}$ "sufficiently" close to the strategy $\mathrm{I}$, defined as $\mathrm{J}=\left[u_{1}, u_{\mathrm{D}}\right.$, $\left.u_{2}\right]$. The mixed net benefit can be defined as $B(\mathrm{I}, \mathrm{J})=B_{G}(\mathrm{I}, \mathrm{J})+B_{C}(\mathrm{~J})=N R$

$\left(\int_{t_{1}}^{t_{2}} f(x) d x\right)\left(\int_{u_{1}}^{u_{2}} f(x) d x\right)+B_{C}(\mathrm{~J})$, where $B_{C}(\mathrm{~J})=B_{C}\left(u_{1}, u_{\mathrm{D}}, u_{2}\right)$ as defined earlier. Then $\mathrm{I}$ is stable if $B(\mathrm{I}, \mathrm{J})<B(\mathrm{I}, \mathrm{I})$ for each $\mathrm{I} \neq \mathrm{J}$. (1)

(1)

How
However, for each level of relative grouping benefit (i.e., for each $N R$ ), it compares the
benefit of two strategies: one mass departure versus departure in two subgroups. For simplicity, time costs are kept symmetric (corresponding to $\omega=0.5$ ) and only the optimal solution is sought. The full description and solution of Model II is given in Appendix B.

\section{MODEL II DESCRIPTION: SPLITTING INTO SUBGROUPS}

The model assumes the same situation with the same costs and benefits as Model I. The model assumes the same situation with the same costs and benefits as Model I.

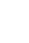




\section{Model I: optimal solution}

Fig. 2 shows which of the three basic scenarios (full, partial and no synchronization) brings the highest net benefit for specific combinations of $N R$ and $\omega$. Most of the parameter space is occupied by either no synchronization (the area below the lower full line) or full synchronization (the area above the upper full line) while partial synchronization is superior only within the narrow croissant-shaped area. As $\omega$ deviates more and more from 0.5 , full synchronization becomes the most prominent strategy. This is because for $\omega$ near zero or one, departing after or before the individual ideal time, respectively, gets almost no penalty and thus animals can cheaply achieve a common departure by waiting very late or by acting very prematurely.

Fig. 2 also maps (in grades of gray shading) the net benefits achieved by the optimal strategies. Higher net benefits can be harvested (for the same value of parameter $N R$ ) for extreme values of $\omega$, where either premature action or delay are cheap and full synchronization is therefore easily achieved by agreeing to a very early or very late common departure

\section{Model I: stable solution}

Fig. 3 illustrates the distribution of stable solutions across the parameter space. Similarly to the optimal solutions, there is a croissant-shaped area (delimited by dashed lines in Fig 3) within which partial synchronization is a stable strategy. Above the croissant, full synchronization is stable. The lower boundary for partial synchronization and the boundary between partial and full synchronization are both shifted upwards (specifically, to twice as high $N R$ ) in comparison with the optimal solution. That is, the stable solution dictates a lower degree of synchronization than the optimal solution in a large area of the parameter space, including a place where the optimal solution prescribes full synchrony while the stable solution is no synchrony at all (Fig. 4). In this area, the stable strategy brings substantially lower net benefit than the optimal one (Fig. 4). Why this is so? An animal should participate in the mass departure only if the benefit outweighs the cost. The cost of improper timing is always paid solely by the specific individual, but there are two kinds of benefits: one goes to the animal itself (as it is part of the synchronized subgroup) and another goes to every synchronized animal because through the contribution of the focal animal, the synchronized 
subgroup increases in size. In the optimal solution, where the costs and benefits are averaged over the group, both types of benefits enter the equation and they are able to pay for higher timing cost, thus drawing more of the animals from the tails into the synchronization. In the stable solution, only the first type of benefit counts and thus more animals will opt out the synchrony.

The second difference between the stable and the optimal solutions is that zero synchronization is a stable strategy across all the parameter space, and not only below the croissant. In the areas of higher and high $N R$, i.e. within and above the croissant, two stable strategies coexist: the partial/full synchronization and the zero synchronization, of which the former brings higher net benefit. Zero synchronization is stable because once it becomes established, each animal departs at a different time and therefore it is difficult for a small fraction of animals to set foot with an alternative strategy, as their attempts to synchronize get no support from the majority.

\section{Splitting into subgroups}

Splitting into two subgroups is never an optimal strategy because for any given $N R$, the optimal strategy with one central departure always brings higher net benefit than the best twodeparture option (Fig. 5).

\section{Repeated synchronizations}

What happens when the synchronization challenge is repeated? If the grouping benefit/consensus cost ratio $(N R)$ is high, then no animals are shed and the group remains of the same size across a single or repeated challenges. Low $N R$ leads to zero synchronization and therefore to immediate dispersal of the group on the first challenge. The interesting case occurs with partial synchronization during which the group size is trimmed (Fig. 6). What happens on the next encounter depends on what is the distribution of ideal times in the downsized group. To simplify the solution, we restrict the analysis of this problem to symmetric costs of time (corresponding to $\omega=0.5$ in the previous model) and to the optimal solution.

If each animal keeps its ideal time from one challenge to the next then during partial synchronization both the group size and the variability of the density distribution of ideal 
times is also trimmed (Fig. 6b), but the latter more so because the costly tails of the distribution are shed. Therefore, the grouping benefit/consensus cost ratio increases and the group size stabilizes at a reduced size. The derivation of this result is given in Appendix C. We call this option the Assortment scenario as it results in a subgroup where members are more alike in terms of their time preferences than in the original group.

If partial synchronization leads to a smaller group in which the variation of ideal times remains as large as before the reduction (i.e. individuals do not keep their individual times from one challenge to another, Non-Assortment scenario), then the consensus costs remain unaltered while grouping benefits fall (Fig. 6c). Consequently, the group is reduced further during next challenge or challenges until it disintegrates (see Appendix C).

\section{Minimal group size}

It follows from the analysis of repeated synchronizations that in Fig. 2, that the upper border of the partial synchronization area delineates the minimal $R$ value for which the group of size $N$ remains cohesive in the Non-Assortment scenario, and the lower border demarcates group cohesion boundary for the Assortment scenario. In the analysis of Models I and II, we have assumed that the group size was fixed, and the relative "per animal" grouping benefit $R$ was varied. Conversely, the chart can be understood as illustrating how the stability of a group depends on its size $N$, for a given "per animal" grouping net benefit $R$ (Fig. 7).

\section{DISCUSSION}

Our models yield three main insights into the links between the grouping-benefitversus-consensus-costs trade-off, behavioural synchronization and group size and stability.

First, the results indicate that synchronization of departures will often be an all-ornothing phenomenon. Model predicts that if the benefit of staying in a group of animals depends linearly on the size of the group (which is the assumption of the model) and the cost of staying in the group varies quasinormally among the group members, then the group will most of the time either switch behaviour synchronously and thus stay together, or all individuals will behave independently and the group will disintegrate. The cases when animals at the tails of the distribution will act solitarily and the rest of the group in synchrony are predicted to be rare. In other words, the overall grouping-benefit-to-consensus-costs ratio 
is predicted to decide, in most cases, for all animals to either depart synchronously or individually, with individual differences such as boldness/fearfulness (Reale et al., 2007) or satiation (Rands et al., 2004) playing only a marginal role in this situation. Moreover, Model II shows that splitting into two subgroups brings lower net benefit than the central synchronization in one group, indicating that synchronization challenges will not lead to separation into smaller units. Finally, the analysis of repeated synchronization events with no assortment shows that even when partial synchronization occurs, the group will quickly diminish and disintegrate.

Second, Model I shows that when individuals in groups behave selfishly, a much weaker synchronization, higher probability of group disintegration and lower net benefits are predicted than in groups that behave optimally from the overall fitness point of view. This is due to the fact that the cost of staying with the group is carried individually by each animal, whereas benefits from the presence of the individual in the group are cashed both by the animal in question (it enjoys the company of others) and by all other group members (because the groups stays larger). Therefore, if the animal counts in only its own benefits (the stable solution), it is prepared to expend less costs to stay in the group than if everybody's benefits are taken into account. Moreover, Model I documents that zero synchronization is a stable solution all across the parameter space. Why zero synchronization is stable everywhere and full synchronization is not? Full synchronization is unstable with low $N R$ since any individual can, independently of what others do, default from the synchrony, leave at its individual ideal time and cash in the benefit of not paying any penalty for improper timing. In the contrary, skipping individually from zero synchronization to a partial or full synchronization just by individual action is impossible, since in order to achieve synchrony, you need pals to go with you. The existence of zero synchronization as a solution for the entire parameter space in the stable, but not in the optimal solution further underscores the general implication of our models that evolutionary stable regime of synchronized departures will often bring substantially lower net benefit than the optimal one.

The optimal-stable solution dichotomy shows that there is a Prisoners Dilemma type of game underlying our models (Fletcher and Zwick, 2007). If an animal plays Stable against a group that plays Optimal, it gets a better pay-off than if it would play Optimal. However, as animals shift from the Optimal to the Stable strategy, the whole group gradually starts playing Stable, and everybody ends with a worse pay-off than it would get if the whole group kept playing Optimal. The combination of our two models thus predicts that sub-optimally low 
degree of synchronization will be frequently observed in departures and other major cohesion influencing behavioural switches unless the optimal strategy could be maintained by altruismsupporting mechanisms such as relatedness, reciprocity or assortment (Fletcher and Zwick, 2006, 2007; Frommen et al., 2007; Fischhoff et al., 2009).

Third, and perhaps most interestingly, the current study brings to light the phenomenon of minimal stable group size. To our knowledge, this is the first study pointing to this phenomenon and identifying synchronization of behaviour as its driving force. Our results indicate that the need to synchronize the starts and stops of movements will in many cases set a minimal threshold group size below which group cohesion will no longer be beneficial. The situation is especially clear in the non-assortment scenario, where groups above a size that makes full synchronization stable are predicted to stay together while smaller groups should disintegrate. Thus the model predicts that when per capita grouping benefits are high, the average group size should decrease because small groups will be able to withstand synchronization challenges.

How does this seemingly paradoxical prediction arise? The synchronization cost differs substantially from other types of grouping costs considered so far. In most of the models and reviews published to date, the costs to an individual of being in a group were thought in terms of foraging interference (Stillmann et al., 2000; Sansom et al., 2007), reproductive interference (Westneat and Sherman, 1997), proximity-transmitted pathogens (Côté and Pohlin, 1995) or similar factors. For instance, in their influential book, Krause and Ruxton (2002, page 41) list twelve different types of grouping costs, but do not mention synchronization cost. The costs listed by Krause and Ruxton were assumed to increase with increasing group size, often at an accelerating rate (Fig. 8a). In contrast, the synchronization cost in our model remains constant, irrespective of group size (Fig. 8b). This is because the synchronization cost to an individual is given by the time distance between its ideal time and the time of common departure and this distance neither shrinks nor expands if more or fewer other animals also pay their costs. Previous models assumed that even very small grouping is better than solitary life and sought to find the optimal and the maximal stable group size (Fig. 8a). Our model shows that when the need to synchronize is the major cost of grouping, then net benefit may be lower in small groups than in solitary animals and a certain group size is needed for the grouping benefits to offset the synchronization costs (Fig. 8b). It remains to be investigated how important role the movement synchronization costs play in determining animal group sizes in nature. In some cases, it is possible that the synchronization and other 
types of grouping costs will combine so that the resulting cost function, together with depreciating grouping benefits, will set both minimum and maximum profitable group size (Fig. 8c). Our results also show that smaller groups are stable if animals assort according to a feature that determines their preferred departure times such as boldness/shyness (Croft et al., 2009) or body size (Ruckstuhl, 1999; Hoare et al., 2000).

The predictions of our models are linked to two crucial assumptions, namely that the grouping benefit increases linearly with the group size, rather than according to a depreciating function, and that the heterogeneity in ideal departure times is unimodally distributed. If the first assumption is relaxed, regular group splitting might occur in the form of a fission-fusion dynamics (Conradt and Roper, 2000; Pays et al., 2007). If ideal times are not unimodally distributed, more permanent splitting will probably happen, such as in the case of sexual segregation (Ruckstuhl and Kokko, 2002). Also, the total constancy of synchronization cost over all group sizes is an idealization since in very small groups with quorum decisionmaking, individual animals will have some influence on the time of common departure and cost will be consequently somewhat lower. Further, our model only addresses possible decrease in size, splitting or dissolution of already existing groups, but not their formation or increase through individuals joining. Finally, the models only address major behavioural transitions in a world where being member of a group is an all-or-nothing state that has to be defended or abandoned during a challenge, rather than a state defined by a continuous proximity in space (Ruckstuhl and Kokko, 2002; Rands et al., 2004) or continuous degree of synchronization in time (Šárová et al., 2007; Michelena et al., 2008). Nevertheless, Models I and II apply not only to timing, but also to any situation where a group, in order to stay together, must reach a consensus along a continuous variable such as gradient in space, escalation of conflict with other group etc.

In conclusion, this study documents that synchronization of activity switches such as departures brings a specific type of grouping costs that has specific consequences. First, it may most often cause groups to either stay together or completely dissolve during synchronization challenges. Second, it implies that groups will often react to synchronization challenges with lower-than-optimal synchronization because of the Prisoners-Dilemma type of payoff inherent to the situation. And third, synchronization cost will often set a limit of a smallest group size below which grouping is no longer advantageous over the solitary condition.

\section{ACKNOWLEDGEMENTS}


Supported by grant IAA601410612 from GA AV ČR and grant MZE0002701404.

\section{REFERENCES}

Amé, J.M., Halloy, J., Rivault, C., Detrain, C., Deneubourg, J.L., 2006. Collegial decision making based on social amplification leads to optimal group formation. PNAS 103(15), 58355840., doi:10.1073/pnas.0507877103.

Conradt, L., List, C. 2009. Group decisions in humans and animals: a survey. Phil. Trans. R. Soc. B 364(1518), 719-742., doi: 10.1098/rstb.2008.0276.

Conradt, L., Roper, T.J., 2000. Activity synchrony and social cohesion: a fission-fusion model. Proc. R. Soc. London B 267(1458), 2213-2218.

Conradt, L., Roper, T.J., 2003. Group decision-making in animals. Nature 421(6919), 155158., doi:10.1038/nature01294

Conradt, L., Roper, T.J., 2005. Consensus decision making in animals. Trends Ecol. Evol. 20(8), 449-456., doi:10.1016/j.tree.2005.05.008.

Conradt, L., Roper, T.J., 2007. Democracy in animals: the evolution of shared group decisions. Proc. R. Soc. London B 274(1623), 2317-2326., doi:10.1098/rspb.2007.0186

Côté, I.M., Poulin, R., 1995. Parasitism and group size in social animals - a meta-analysis. Behav. Ecol. 6(2), 159-165.

Couzin, I.D., Krause, J., Franks, N.R., Levin, S.A., 2005. Effective leadership and decisionmaking in animal groups on the move. Nature 433(7025), 513-516., doi:10.1038/nature03236.

Croft, D.P., Krause, J., Darden, S.K., Ramnarine, I.W., Faria, J.J., James, R., 2009.

Behavioural trait assortment in a social network: Patterns and implications. Behav. Ecol. Sociobiol., 63(10), 1495-1503., doi: 10.1007/s00265-009-0802-x.

Dostálková, I., Špinka, M., 2007. Synchronization of behaviour in pairs: the role of communication and consequences in timing. Anim. Behav. 74(6), 1735-1742., doi:10.1016/j.anbehav.2007.04.014.

Fischhoff, I.R., Dushoff, J., Sundaresan, S.R., Cordingley, J.E., Rubenstein, D.I., 2009. Reproductive status influences group size and persistence of bonds in male plains zebra 
(Equus burchelli). Behav. Ecol. Sociobiol., 63(7), 1035-1043., doi: 10.1007/s00265-0090723-8.

Fletcher, J. A. and Zwick, M., 2006. Unifying the theories of inclusive fitness and reciprocal altruism. Am. Nat. 168(2), 252-262.

Fletcher, J. A. and Zwick, M., 2007. The Evolution of Altruism: Game theory in multilevel selection and inclusive fitness. J. Theor. Biol. 245(1), 26-36., doi:10.1016/j.jtbi.2006.09.030.

Frommen, J.G., Mehlis, M., Brendler, C., Bakker, T.C.M., 2007. shoaling decisions in threespined sticklebacks (gasterosteus aculeatus) - familiarity, kinship and inbreeding. Behav. Ecol. Sociobiol., 61(4), 533-539.

Hoare, D.J., Krause, J., Peuhkuri, N., Godin, J.G.J., 2000. Body size and shoaling in fish. J. Fish Biol., 57(6), 1351-1366

Krause, J., Ruxton, G. (Eds), 2002. Living in Groups, Oxford University Press, Oxford.

Martín, J., Luque-Larena, J.J., Lopez, P., 2006. Collective detection in escape responses of temporary groups of Iberian green frogs. Behav. Ecol. 17(2), 222-226., doi: 10.1093/beheco/arj024.

Michelena, P., Gautrais, J., Gérard, J. F., Bon, R., and Deneubourg, J. L., 2008. Social cohesion in groups of sheep: effect of activity level, sex composition and group size. Appl. Anim. Behav. Sci. 112(1-2), 81-93., doi:10.1016/j.applanim.2007.06.020.

Pays, O., Benhamou, S., Helder, R., Gérard, J.F., 2007. The dynamics of group formation in large mammalian herbivores: an analysis in the european roe deer. Anim. Behav. 74(5), 14291441., doi:10.1016/j.anbehav.2007.02.012.

Rands, S.A., Cowlishaw, G., Pettifor, R.A., Rowcliffe, J.M., Johnstone, R.A., 2003.

Spontaneous emergence of leaders and followers in foraging pairs. Nature 423(6938), 432434., doi: 10.1038/nature01630.

Rands, S. A., Pettifor, R. A., Rowcliffe, J. M., and Cowlishaw, G., 2004. State-dependent foraging rules for social animals in selfish herds. Proc. R. Soc. London B 271(1557), 26132620., doi:10.1098/rspb.2004.2906. 
Reale, D., Reader, S. M., Sol, D., Mcdougall, P. T., and Dingemanse, N. J., 2007. Integrating animal temperament within ecology and evolution. Biol. Rev. 82(2), 291-318., doi: 10.1111/j.1469-185X.2007.00010.x.

Ruckstuhl, K.E., 1999. To synchronise or not to synchronise: a dilemma for young bighorn males? Behaviour, 136(), 805-818

Ruckstuhl, K.E., Kokko, H., 2002. Modelling sexual segregation in ungulates: effects of group size, activity budgets and synchrony. Anim. Behav. 64(6), 909-914., doi:10.1006/anbe.2002.2015.

Sansom, A., Cresswell, W., Minderman, J., and Lind, J., 2008. Vigilance benefits and competition costs in groups: do individual redshanks gain an overall foraging benefit? Anim. Behav. 75(6), 1869-1875., doi:10.1016/j.anbehav.2007.11.005.

Šárová, R., Špinka, M., and Panamá, J. L. A., 2007. Synchronization and leadership in switches between resting and activity in a beef cattle herd a case study. Appl. Anim. Behav. Sci. 108(3-4), 327-331., doi:10.1016/j.applanim.2007.01.009.

Sirot, E., Touzalin, F., 2009. Coordination and synchronization of vigilance in groups of prey: the role of collective detection and predators' preference for stragglers. Am. Nat. 173(1), $47-$ 59., doi: 10.1086/593358.

Stillman, R.A., Goss-Custard, J.D., Alexander, M.J., 2000. Predator search pattern and the strength of interference through prey depression. Behav. Ecol. 11(6), 597-605.

Westneat, D.F., Sherman, P.W., 1997. Density and extra-pair fertilizations in birds: a comparative analysis. Behav. Ecol. Sociobiol. 41(4), 205-215.

Ydenberg, R.C., Dill, L.M., 1986. The economics of fleeing from predators. Adv. Study Behav. 16, 229-249. 
Fig. 1 An example of the density and distribution functions $f(t)$ and $F(t)$ in Model I. This specific function was used for calculating results displayed in Figs. 2 to 6 . The dotted line and the left scaling on the $y$-axis displays the density function $f(t)$ of the ideal individual times $t$ within the group. The thin solid line and the right scaling on the $y$-axis displays the distribution function $F(t)$, representing the number of animals that are beyond their ideal time $t$. The bold solid line illustrates an example of the two behavioural options available in the model. Animals that have their ideal switch points before time $t_{1}$ and after time $t_{2}$ leave individually at their respective ideal times, while all animals with $t_{1} \leq t \leq t_{2}$ depart together at $t_{D}$. The letters $b, c, d$ denote intervals used for description of the model in Appendix A.

Fig. 2 Optimal strategies and their net benefits as dependent on the parameters $\omega$ and $N R$. The thick lines demarcate boundaries between the areas of zero synchronization, partial synchronization and full synchronization The net benefit increases with the darkness of the shading. The curved lines are isolines of equal levels of net benefit. The net benefit level is described by the number on the isolines.

Fig. 3 Stable strategies, and their net benefits, as dependent on the parameters $\omega$ and $N R$. The two dotted lines demarcate boundaries between the areas of zero synchronization, partial synchronization and full synchronization. The shading and the isolines have the same meaning as in Fig. 2.

Fig. 4 Differences between benefits of stable and optimal strategies in the parameter space $\omega$, $N R$. The thick and dotted lines are those given in Figs. 2 and 3. The darker the shading, the 
higher is the difference in benefit between the optimal and the stable strategy. The curved lines are isolines of equal levels of this difference.

Fig. 5 Net benefits of the one-departure (solid curve) and two-departure (dashed curve) strategies in Model II, as dependent on NR.

Fig. 6. Effect of repeated synchronizations in the case of a 50\% partial synchronization. a) Original density function $f(t)$ (dashed line, left scaling on the $y$-axis) and cumulative distribution function $F(t)$ (full line, right scaling on the $y$-axis) before the partial synchronization. After the partial synchronization, only half of the animals are left in the group and therefore the functions change shape to b) in the case of Assortment scenario and to c) in the case of Non-Assortment scenario. $N=$ number of animals in the group, $\sigma=$ variability of the density distribution. See text for more explanation.

Fig. 7. Group stability as dependent on the group size. For this example, the $R$ parameter was fixed at $R=0.02$.

Fig. 8. Grouping benefits and costs as dependent on group size according to a) previous models published before this study, b) this study and c) possible combined scenario. Solid lines $=$ grouping benefit, dashed lines $=$ grouping cost. $N_{\min }, N_{\max }=$ minimal and maximal group size in which net benefit is higher than in solitary animals. $N_{\text {opt }}=$ group size bringing the highest benefit. 


\section{ASSUMPTIONS ABOUT IDEAL SWITCH TIMES}

We suppose that:

1. We have the set of $N$ animals.

2. There exist the ideal switch points denominated as $t_{i}^{*}$ for the animal $i, 1 \leq i \leq N$ that are the realizations of the random variable $T^{*}$, which is defined by its continuous density function $f$.

3. The function $f$ has the following properties:
a. $f$ is symmetric in 0 .
b. $f(t)>0$ in the interval $(-1,1), f(t)=0$ for $t \notin(-1,1)$.
c. $f^{\prime}(t) \geq 0$ in the interval $(-1,0), f^{\prime}(t)<0$ in the interval $(0,1)$

d. $\int_{-1}^{1} f(t) d t=1$.

\section{ASSUMPTIONS ABOUT STRATEGIES}

A strategy $I=[b, c, d]$ is defined by costants $b, c, d$

$$
b=t_{1}-(-1)=t_{1}+1
$$$$
c=t_{D}-t_{1}
$$$$
\left.d=t_{2}-t_{\mathrm{D}} \text { (see Fig. } 1\right) \text {, }
$$

Where $b+c+d \leq 2, b \geq 0, c \geq 0, d \geq 0$. The behaviour of an individual $i$ with the ideal switch time $t_{i}^{*}$ is determined by the position of $t_{i}^{*}$ on the interval $(-1,1)$, according to Table A.1

\section{ASSUMPTIONS ABOUT THE NET BENEFIT FUNCTION}


Let $U(x, b, c, d)$ be the utility function for ideal switch point placed in position $x$ on time axis. Let it be continuous function to the exclusion of points $-1+b,-1+b+c,-1+b+c+d$. Let it be defined by the following Table A1.

Table A1. Definitions of behaviours and of the utility function. For synchronized departures, the first part of the utility function quantifies the grouping benefit, the second quantifies the synchronization costs. $R, \omega$ are parameters, $R \geq 0,1 \geq \omega \geq 0$

\begin{tabular}{|l|l|l|}
\hline $\begin{array}{l}\text { Intervals defining position of } \\
\text { ideal switch time point }\end{array}$ & Behaviour & $\begin{array}{l}\text { Utility function } \\
U(x, b, c, d)\end{array}$ \\
\hline$t_{i}^{*} \in(-1,-1+b)$ & $\begin{array}{l}\text { non-synchronized departures, } \\
\text { each at individual } t_{i}^{*}\end{array}$ & 0 \\
\hline$t_{i}^{*} \in(-1+b,-1+b+c)$ & $\begin{array}{l}\text { synchronized departure } \\
\text { at }-1+b+c\end{array}$ & $N R\left(\int_{-1+b}^{-1+b+c+d} f(x) d x\right)-\omega((-1+b+\mathrm{c})-\mathrm{x})$ \\
\hline $\begin{array}{l}t_{i}^{*} \in(-1+b+c,-1+b+c+ \\
d)\end{array}$ & $\begin{array}{l}\text { synchronized departure } \\
\text { at }-1+b+c\end{array}$ & $N R\left(\int_{-1+b}^{-1+b+c+d} f(x) d x\right)-(1-\omega)(x-(-1+b+c))$ \\
\hline$t_{i}^{*} \in(-1+b+c+d, 1)$ & $\begin{array}{l}\text { non-synchronized departures, } \\
\text { each at individual } t_{i}^{*}\end{array}$ & 0 \\
\hline
\end{tabular}

- The net benefit $B$ for given $b, c, d$ and for given position of ideal switch point (e.g. for given $x$ on time axis) is defined $B(x, b, c, d)=f(x) U(x, b, c, d)$ where $f(x)$ is the density function defined above.

- The net benefit $B$ for the whole group is defined as

$$
B(b, c, d)=\int_{-1+b}^{-1+b+c} B(x, b, c, d) d x+\int_{-1+b+c}^{-1+b+c+d} B(x, b, c, d) d x=\int_{-1+b}^{-1+b+c} f(x) U(x, b, c, d) d x+
$$$$
\int_{-1+b+c}^{-1+b+c+d} f(x) U(x, b, c, d) d x
$$ 
572

573

\section{CALCULATION OF OPTIMAL STRATEGIES}

\subsection{Derivation of the net benefit function}

$$
\begin{aligned}
& B(b, c, d)=-\omega(-1+b+c) \int_{-1+b}^{-1+b+c} f(x) d x+\omega \int_{-1+b}^{-1+b+c} x f(x) d x+(1-\omega)(-1+b+c) \int_{-1+b+c}^{-1+b+c+d} f(x) d x- \\
& (1-\omega) \int_{-1+b+c}^{-1+b+c+d} x f(x) d x+N R\left(\int_{-1+b}^{-1+b+c+d} f(x) d x\right)^{2} \\
& \text { 4.2. Conditions for the local maxima of net benefit. }
\end{aligned}
$$

\subsection{Conditions for the local maxima of net benefit.}

To obtain internal maxima we have the following conditions inside of the simplex $b+c+d \leq$ $2, b \geq 0, c \geq 0, d \geq 0: \mathrm{d} B / \mathrm{d} b=\mathrm{d} B / \mathrm{d} c=\mathrm{d} B / \mathrm{d} d=0$.

Therefore the following relations must be valid:

$\mathrm{d} B / \mathrm{d} d=f(-1+b+c+d)\left(2 N R \int_{-1+b}^{-1+b+c+d} f(x) d x-(1-\omega) d\right)=0$

$\mathrm{d} B / \mathrm{d} c=\mathrm{d} B / \mathrm{d} d-\omega \int_{-1+b}^{-1+b+c+d} f(x) d x+\int_{-1+b+c}^{-1+b+c+d} f(x) d x=0$

$\mathrm{d} B / \mathrm{d} b=\mathrm{d} B / \mathrm{d} c+f(-1+b)\left(\omega c-2 N R \int_{-1+b}^{-1+b+c+d} f(x) d x\right)=0$

As $f(-1+b+c+d)>0$ inside the simplex, we can derive the following relations

$$
\int_{-1+b}^{-1+b+c} f(x) d x=\frac{\omega(1-\omega)}{2 N R} c
$$

$\int_{-1+b+c}^{-1+b+c+d} f(x) d x=\frac{\omega(1-\omega)}{2 N R} d$,

$\int_{-1+b}^{-1+b+c+d} f(x) d x=\frac{\omega(1-\omega)}{2 N R}(c+d)$

$c=\frac{(1-\omega) d}{\omega}$ 
According to the conditions for the function $f$ and according to the mean value theorem we can see that $1 / 2 \leq \frac{\omega(1-\omega)}{2 N R} \leq f(0)$

As slopes of the lines in the right sides of relations (A.4) - (A.6) are the same, the solution of this system is unique. That means there exists unique triplet $[b, c, d]$ inside of the simplex $b+c+d \leq 2, b \geq 0, c \geq 0, d \geq 0$ that can be maximum of $B$. This fact is valid for each $[\omega, N R], \omega(1-\omega) \geq N R \geq \frac{\omega(1-\omega)}{2 f(0)}$.

\subsection{Other maxima.}

Other maxima are placed on the border of the simplex. The possible points of maxima are $b \geq 0, c=d=0$, and $b=0, c+d=2$. The first case describes the set of non-synchronized switches, the second case describes the set of totally synchronized switches.

\subsection{Conclusion - the points of maxima of optimal strategies}

- ZERO SYNCHRONIZATION. If $N R \leq \frac{\omega(1-\omega)}{2 f(0)}$, then zero synchronization strategy $[b, 0,0]$, is the optimal strategy and brings the net benefit. $B(b, 0,0)=0$.

PARTIAL SYNCHRONIZATION. If $\frac{\omega(1-\omega)}{2 f(0)}<N R<\omega(1-\omega)$, then partial synchronization strategy $[b, c, d], b+c+d<2, b>0, c>0, d>0, c=\frac{(1-\omega) d}{\omega}$, such that relations (A.4) - (A.7) are valid, is the optimal strategy and brings the net benefit 
595

596

597

598

599

600

601

602

603

604

605

606

607

608

609

610

611

612

613

614

$$
B(b, c, d)=\omega \int_{-1+b}^{-1+b+c} x f(x) d x-(1-\omega) \int_{-1+b+c}^{-1+b+c+d} x f(x) d x+N R\left(\int_{-1+b}^{-1+b+c+d} f(x) d x\right)^{2}
$$

- $\quad$ FULL SYNCHRONIZATION. If $N R \geq \omega(1-\omega)$, then the full synchronization strategy

- $\quad[0, c, d], c+d=2$, such that $c=\frac{(1-\omega) d}{\omega}$, is the optimal strategy and brings the net benefit (1)

$B(0, c, 2-c)=N R-\int_{-1+c}^{1} x f(x) d x$ 3

\section{CALCULATION OF STABLE STRATEGIES}

\subsection{Derivation of the benefit functions.}

Let $I=[b, c, d]$ and $J=[p, q, r]$ are two strategies. Benefit of the strategy $I$, in the group, where strategy $J$ is present can be expressed by

$B(\mathrm{I}, \mathrm{J})=-\omega(-1+p+q) \int_{-1+p}^{-1+p+q} f(x) d x+\omega \int_{-1+p}^{-1+p+q} x f(x) d x+(1-\omega)(-1+p+q) \int_{-1+p+q}^{-1+p+q+r} f(x) d x-(1-$

$\omega) \int_{-1+p+q}^{-1+p+q+r} x f(x) d x+N R\left(\int_{-1+b}^{-1+b+c+d} f(x) d x\right)\left(\int_{-1+p}^{-1+p+q+r} f(x) d x\right)$

If $I$ is replaced by $J$, then

$B(\mathrm{I}, \mathrm{I})=-\omega(-1+b+c) \int_{-1+b}^{-1+b+c} f(x) d x+\omega \int_{-1+b}^{-1+b+c} x f(x) d x+(1-\omega)(-1+b+c) \int_{-1+b+c}^{-1+b+c+d} f(x) d x-(1-$

$\omega \int_{-1+b+c}^{-1+b+c+d} x f(x) d x+N R\left(\int_{-1+b}^{-1+b+c+d} f(x) d x\right)^{2}$

14 We define a function 


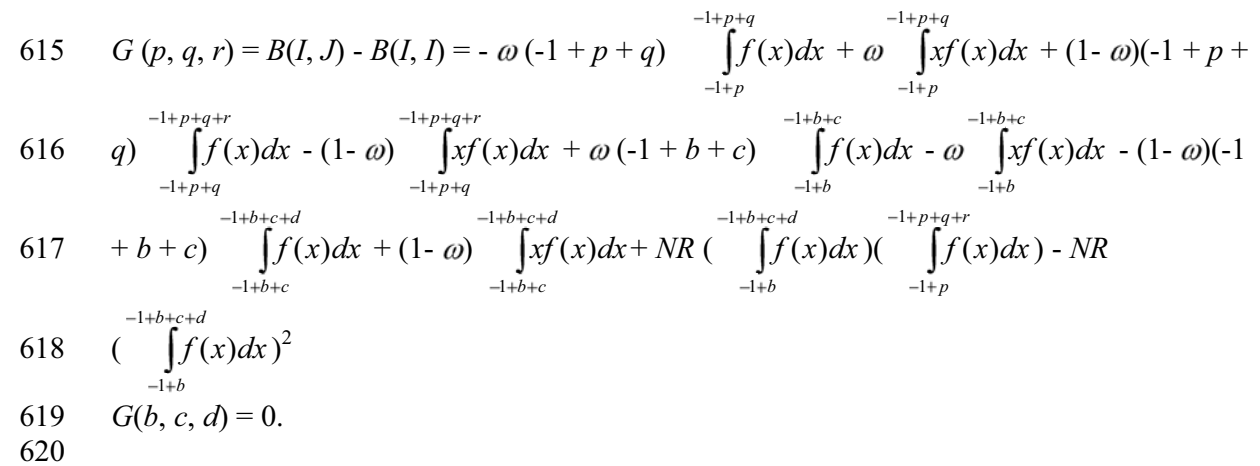

621 Strategy $I$ is stable if and only if $G(p, q, r)<0$ for $p \neq b, q \neq c, r \neq d$ and $J=I$ is local 622 maximum of $G, G(b, c, d)=0$.

\subsection{Conditions for the local stability}

By the same procedure as in point 2 we will try to find maxima of $G$ inside of simplex $p+q+$

$r \leq 2, p \geq 0, q \geq 0, r \geq 0$, where in addition $b+c+d \leq 2, b \geq 0, c \geq 0, d \geq 0$.

628

629

630

631

632

633 $634>1$

635 Here strategy $I$ is stable, if, in agreement with procedure in point 2,

Conditions similar to (A.1) - (A.3) are

$\mathrm{d} G / \mathrm{d} r=f(-1+p+q+r)\left(N R \int_{-1+b}^{-1+b+c+d} f(x) d x-(1-\omega) r\right)$

$\mathrm{d} G / \mathrm{d} q=\mathrm{d} G / \mathrm{d} r-\omega \int_{-1+p}^{-1+p+q+r} f(x) d x+\int_{-1+p+q}^{-1+p+q+r} f(x) d x$

$\mathrm{d} G / \mathrm{d} p=\mathrm{d} G / \mathrm{d} q+f(-1+p)\left(\omega q-N R \int_{-1+b}^{-1+b+c+d} f(x) d x\right)$
At the point of maxima the function $G$ must be concave, that means in our case $\frac{\partial^{2} G}{d p^{2}}(\mathrm{~b}, \mathrm{c}, \mathrm{d})$

$=(1-\omega) f(-1+\mathrm{b}+\mathrm{c}+\mathrm{d})-f(-1+\mathrm{b}+\mathrm{c})+\omega f(-1+\mathrm{b})<0$. That means $0<b<1,2>b+c+d$

$2 \omega(1-\omega) \geq N R \geq \frac{\omega(1-\omega)}{f(0)}, c=\frac{(1-\omega) d}{\omega}, \omega \int_{-1+b}^{-1+b+c+d} f(x) d x=\int_{-1+b+c}^{-1+b+c+d} f(x) d x$, 
637

638

\section{$639 \quad$ 5.3. Other stable strategies}

640

641

642 $\mathrm{dG} / \mathrm{d} r-\lambda_{1} n_{1}=0$

$\mathrm{d} G / \mathrm{d} q-\lambda_{2} n_{2}=0$

$\mathrm{d} G / \mathrm{d} p-\lambda_{3} n_{3}=0$ $B(b, 0,0)=0$.

$N R \int_{-1+b}^{-1+b+c+d} f(x) d x=(1-\omega) d, b<1$ and $b+c+d>1$

On the border of the simplex $p+q+r \leq 2, p \geq 0, q \geq 0, r \geq 0$ other stable strategies are placed. Here in addition $b+c+d \leq 2, b \geq 0, c \geq 0, d \geq 0$.

If the point $[b, c, d]$ is point of local maximum of the function $\mathrm{G}$ and if we have normal vector $n=\left(n_{1}, n_{2}, n_{3}\right)$ to the border of the simplex $p+q+r \leq 2, p \geq 0, q \geq 0, r \geq 0$ at that point $[b$, $c, d]$, then there exist positive numbers $\lambda_{1}, \lambda_{2}, \lambda_{3}$ so that

Therefore we can conclude results about all maxima of $G$.

\subsection{Conclusion - stable strategies}

The following three strategies (and no other strategy) are locally stable:

- ZERO SYNCHRONIZATION. The zero synchronization strategy $[b, 0,0]$, is stable for any combination of values $R, \omega$ and brings the net benefit 
659 PARTIAL SYNCHRONIZATION. If $\frac{\omega(1-\omega)}{f(0)} \leq N R \leq 2 \omega(1-\omega)$, then partial synchronization strategy $[b, c, d], b+c+d<2, b>0, c>0, d>0, c=\frac{(1-\omega) d}{\omega}$, is stable and brings the net benefit

- $\quad$ FULL SYNCHRONIZATION. If $N R \geq 2 \omega(1-\omega)$, then the full synchronization 


\section{ASSUMPTIONS ABOUT IDEAL SWITCH TIMES}

The assumptions are the same as in Model I in Appendix A.

\section{ASSUMPTIONS ABOUT STRATEGIES}

A strategy $I=[r, s]$ is defined by costants $r, s$ where $r \geq 0, s \geq 0, r+s \leq 1$. The behaviour of an individual $i$ with the ideal switch time $t_{i}^{*}$ is determined by the position of $t_{i}^{*}$ on the interval (-1, 1), according to Table B.1

\section{ASSUMPTIONS ABOUT THE NET BENEFIT FUNCTION}

Let $U(x, r, s)$ be the utility function for ideal switch point placed in position $x$ on time axis. Let it be continuous function to the exclusion of points $-\mathrm{r}-\mathrm{s},-\mathrm{s}, 0, \mathrm{~s}, \mathrm{r}+\mathrm{s}$. Let it be defined by the following Table B.1.

Table B.1. Definitions of behaviours and of the utility function. For synchronized departures, the first part of the utility function quantifies the grouping benefit, the second quantifies the synchronization costs. $R$ is a parameter, $R \geq 0$.

\begin{tabular}{|l|l|l|}
\hline $\begin{array}{l}\text { intervals defining position of } \\
\text { ideal switch time point }\end{array}$ & Behaviour & $\begin{array}{l}\text { benefit - cost function } \\
U(x, b, c, d)\end{array}$ \\
\hline$t_{i}^{*} \in(-1,-r-s)$ & $\begin{array}{l}\text { non-synchronized departures, } \\
\text { each at individual } t_{i}^{*}\end{array}$ & 0 \\
\hline$t_{i}^{*} \in(-r-s,-s)$ & $\begin{array}{l}\text { synchronized departure } \\
\text { at }-s\end{array}$ & $2 N R \int_{-1+b}^{-1+b+c+d} f(x) d x+(x+s)$ \\
\hline$t_{i}^{*} \in(-s, 0)$ & $\begin{array}{l}\text { synchronized departure } \\
\text { at }-s\end{array}$ & $2 N R \int_{-1+b}^{-1+b+c+d} f(x) d x-(x+\mathrm{s})$ \\
\hline
\end{tabular}




\begin{tabular}{|l|l|l|}
\hline$t_{i}^{*} \in(0, s)$ & $\begin{array}{l}\text { synchronized departure } \\
\text { at } s\end{array}$ & $2 N R \int_{-1+b}^{-1+b+c+d} f(x) d x-(s-x)$ \\
\hline$t_{i}^{*} \in(s, r+s)$ & $\begin{array}{l}\text { synchronized departure } \\
\text { at } s\end{array}$ & $2 N R \int_{-1+b}^{-1+b+c+d} f(x) d x-(x-s)$ \\
\hline$t_{i}^{*} \in(r+s, 1)$ & $\begin{array}{l}\text { non-synchronized departures, } \\
\text { each at individual } t_{i}^{*}\end{array}$ & 0 \\
\hline
\end{tabular}

691

\section{CALCULATION OF OPTIMAL STRATEGIES}

\subsection{Derivation of the benefit function}

$B(r, s)=-2 \int_{s}^{r+s} x f(x) d x+2 s \int_{s}^{r+s} f(x) d x+2 \int_{0}^{s} x f(x) d x-2 s \int_{0}^{s} f(x) d x+2 N R\left(\int_{0}^{r+s} f(x) d x\right)^{2}$

\subsection{Conditions for the local maxima of benefit.}

To obtain internal maxima we have the following conditions inside of the simplex

$r+s \leq 1, r \geq 0, s \geq 0: \mathrm{d} B / \mathrm{d} r=\mathrm{d} B / \mathrm{d} s=0$.

Therefore the following relations must be valid:

$\frac{\partial B 2}{\partial r}=f(r+s) 4 N R\left(\frac{-r}{2 N R}+\int_{0}^{r+s} f(x) d x\right)=0$

$\frac{\partial B 2}{\partial s}=f(r+s) 4 N R\left(\frac{-r}{2 R}+\int_{0}^{r+s} f(x) d x\right)+2 \int_{s}^{r+s} f(x) d x-2 \int_{0}^{s} f(x) d x=0$

Conditions (C.1), (C.2) are true if and only if

$\frac{r}{2 R}=\int_{0}^{r+s} f(x) d x=2 \int_{s}^{r+s} f(x) d x=2 \int_{0}^{s} f(x) d x$

From that $\frac{1}{4 f(0)} \leq N R \leq 1$

\subsection{Other maxima}

Other maxima are placed on the border of the simplex. The possible points of maxima are $r=s=0$, and $r+s=1$. The first case describes the set of non-synchronized switches, the second case describes the set of totally synchronized switches.

2.4. Conclusion - the points of maxima of optimal strategies 
712 There exists interval $(\alpha, \beta) \subset\left(\frac{1}{4 f(0)}, 1\right)$ so that the following points are valid:

713 - ZERO SYNCHRONIZATION. For each $N R, N R \leq \alpha \quad B(0,0)$ is maximum of $B$.

$714 \quad B(0,0)=0$.

715 - PARTIAL SYNCHRONIZATION. For each $N R, \alpha<N R<\beta$, there exists $[r, s], r+$

$716 s<1, r>0, s>0$ so that relations (1) - (2) are valid and $B(r, s)$ is maximum of $B$.

- $\quad$ FULL SYNCHRONIZATION. For each $N R, N R \geq \beta$, there exists

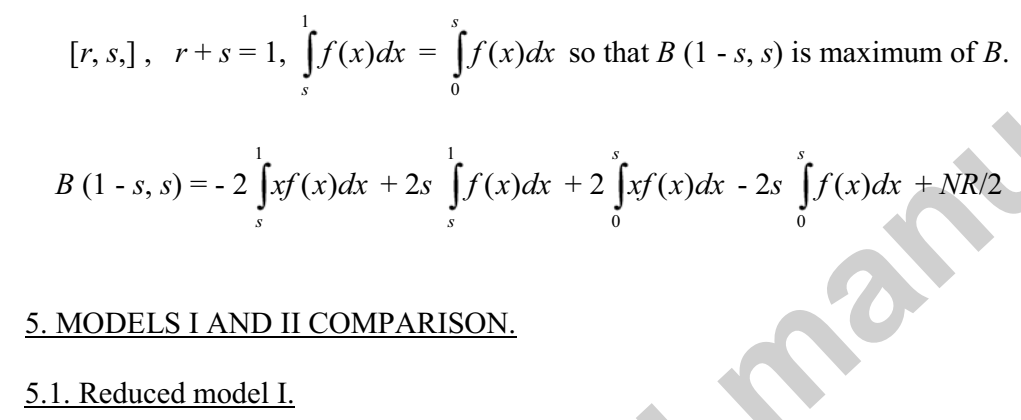

The model described in Appendix A can be reduced to symmetric case, if $\omega=1 / 2$.

We defined the following transformations of variables in the model I:

$-1+b=-e,-1+b+c=0,-1+b+c+d=e$. Then benefit function is function of one variable $e:$

$B(e)=-2 \int_{0}^{e} x f(x) d x+4 N R\left(\int_{0}^{e} f(x) d x\right)^{2}$

The conditions for maxima of $B$ are similar to general model I:

- $\quad$ ZERO SYNCHRONIZATION. For each $N R, N R \leq \frac{1}{4 f(0)}, B(0)$ is maximal. $B(0)=0$. 
736

- $\quad$ PARTIAL SYNCHRONIZATION. For each $N R, \frac{1}{4 f(0)}<N R<0.5$, there exists $0<$ $e<1$, so that $\frac{e L}{4 N Q}=\int_{0}^{e} f(x) d x$ and function $B$ is maximal.

$$
B(e)=-2 \int_{0}^{e} x f(x) d x+4 N R\left(\int_{0}^{e} f(x) d x\right)^{2}
$$

- $\quad$ FULL SYNCHRONIZATION. For each $N R, N R \geq 1 / 2, B(1)$ is maximal.

$$
B(1)=-2 \int_{0}^{1} x f(x) d x+N R
$$

\subsection{Models I and II comparison}

We denoted

$B 1(e) \equiv-2 \int_{0}^{e} x f(x) d x+4 N R\left(\int_{0}^{e} f(x) d x\right)^{2}$ and

$B 2(r, s) \equiv-2 \int_{s}^{r+s} x f(x) d x+2 s \int_{s}^{r+s} f(x) d x+2 \int_{0}^{s} x f(x) d x-2 s \int_{0}^{s} f(x) d x+2 N R\left(\int_{0}^{r+s} f(x) d x\right)^{2}$

Let $(\mathrm{NR})_{1}$ is that value of parameter that $\frac{1}{4}\left(\frac{1}{N R}\right)_{1}=\int_{0}^{1} f(x) d x=1 / 2$. That means $(R)_{1}$ is limit point common for full and partial synchronization in reduced model I.

Let $(R)_{2}$ is that value of parameter that $(N R)_{2}=\beta$ in model II. Therefore the definition of $(N R)_{2}$ in Model II is the same as definition $(N R)_{1}$ in reduced model I.

Then $B 1(1)-B 2(s, 1-s)=-2 \int_{0}^{1} x f(x) d x+1 / 2+2-2 \int_{0}^{s} x f(x) d x-\frac{1-s}{2}=$ $-4 \int_{0}^{s} x f(x) d x+s / 2 \geq 0$. This fact follows from $\int_{s}^{r+s} f(x) d x=\int_{0}^{s} f(x) d x$ and $\frac{r}{2}\left(\frac{1}{N R}\right)_{2}=\frac{1}{2}$

But that means $B 1(e) \geq B 2(r, s)$, where $e$ is maximal point for $B 1$ and $[r, s]$ is maximal point for $B 2$.

\subsection{Conclusion - models I and II comparison.}




\section{SYNCHRONIZATION CHALLENGES}

\section{Assortment scenario}

During the first challenge, the benefit function is, according to Appendix B, part 5.1

$B(e)=-2 \int_{0}^{e} x f(x) d x+4 N R\left(\int_{0}^{e} f(x) d x\right)^{2}$

and the optimal degree of partial synchronization is defined by

$$
\frac{e^{*}}{4 N R}=\int_{0}^{e^{*}} f(x) d x
$$

where $e^{*}$ is the value of $e$ bringing the optimal benefit during the first challenge.

After the first challenge and partial synchronization group size is thus reduced from $N$ to $p N$ where $p$ is the proportion of animals that have departed together on the first challenge and therefore remain in the group

$p=\int_{-e^{*}}^{e^{*}} f(x) d x=2 \int_{0}^{e^{*}} f(x) d x<1$.

All animals with their optimal times $t^{*}{ }_{i}$ within the interval $\left(-1,-e^{*}\right)$ or the interval $\left(e^{*}, 1\right)$ disappear from the group. The the new density function $f_{\text {assort }}(x)$ is defined as

$f_{\text {assort }}(x)=0$ for $x \in\left(-1,-e^{*}\right) \cup\left(e^{*}, 1\right)$,

$f_{\text {assort }}(x)=\frac{1}{p} f(x)$ for $x \in\left(-e^{*}, e^{*}\right)$.

The new optimal degree of partial synchronization is defined by 
$779 \quad \frac{e_{\text {assort }}^{*}}{4 p N R}=\frac{1}{p} \int_{0}^{e_{a \text { aspor }}^{*}} f(x) d x$

780 This equation is identical to (D.2) and therefore

$781 e_{\text {assort }} *=e^{*}$, which means that all animals will depart together during the second challenge

782

783

784

785

786

787

788

789

790

791

792

$793 \quad \frac{e^{*}}{4 N R}=\int_{0}^{e^{*}} f(x) d x$

794

795

796

797

798

799

800 follows and the group size will be stabilized.

\section{Non-Assortment scenario}

The density distribution of ideal times after the first challenge and partial synchronization under the non-assortment scenario $f_{\text {nonassort }}$ remains the same as before the challenge as

$f_{\text {nonassort }}(x)=f(x)$ for $\mathrm{x} \in(-1,1)$

From Appendix B we have for the partial synchronization during the first challenge

and similarly for second challenge

$\frac{e_{\text {nonassort }}^{*}}{4 p N R}=\int_{0}^{e_{\text {nonasort }}^{*}} f_{\text {nonassort }}(x) d x=\int_{0}^{e_{\text {nonasort }}^{*}} f(x) d x$

The function $\alpha(e)=\int_{0}^{e} f(x) d x / \frac{e}{4 N R}$ is decreasing and from (D.3) and (D.4) we have $\alpha\left(e^{*}\right)=1>\alpha\left(e_{\text {nonassort }} *\right)=1 / p$ 
801

802 Therefore $e_{\text {nonassort }}^{*}<e^{*}$

803

804 and consequently a lower proportion of $p_{\text {nonassort }}<p$ will depart together on the second

challenge, until eventually $e_{\text {nonassort }} *=p_{\text {nonassort }}=0$ and the group will dissolve.

806

807

For any given value of parameter $R$, the optimal strategy of the reduced one-departure model

808

brings higher net benefit than the optimal strategy for the two-departure model II. 


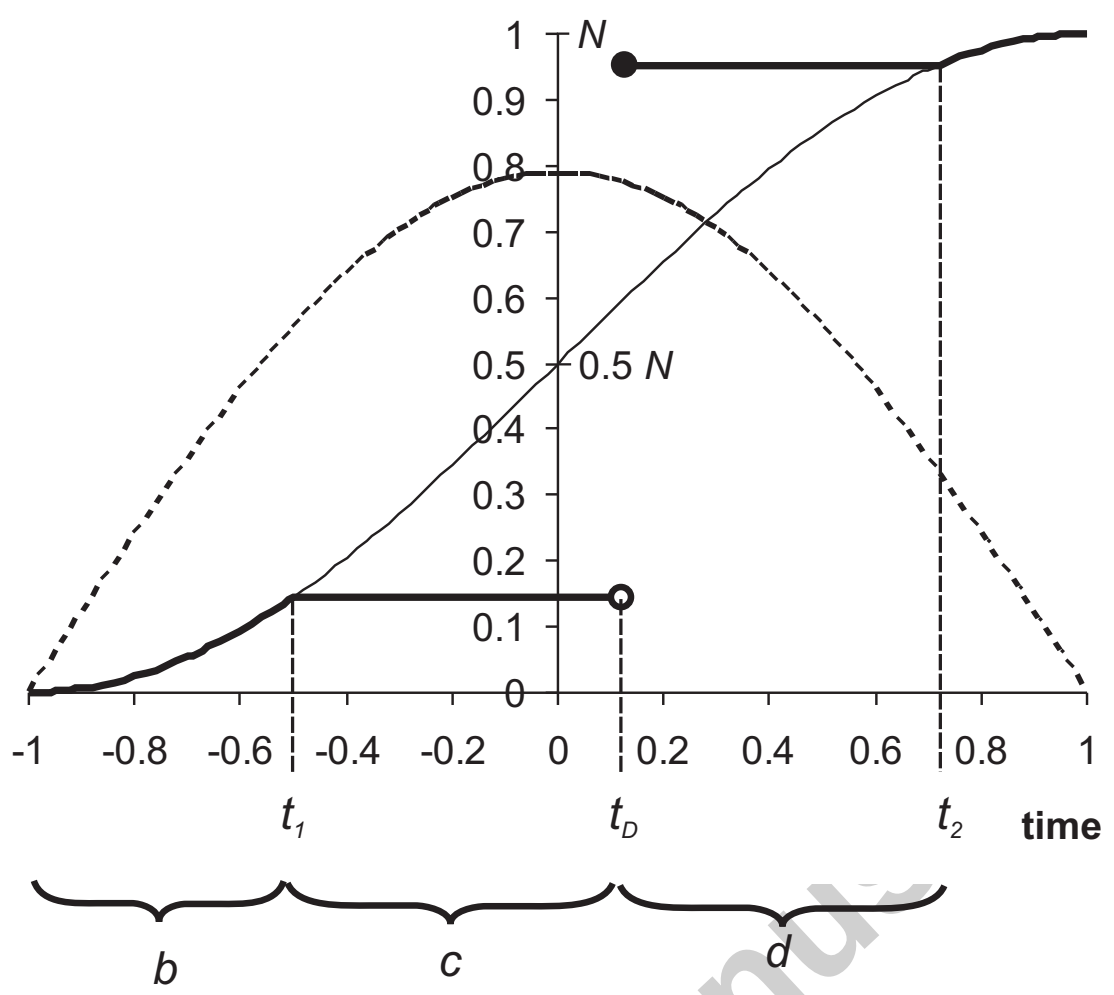




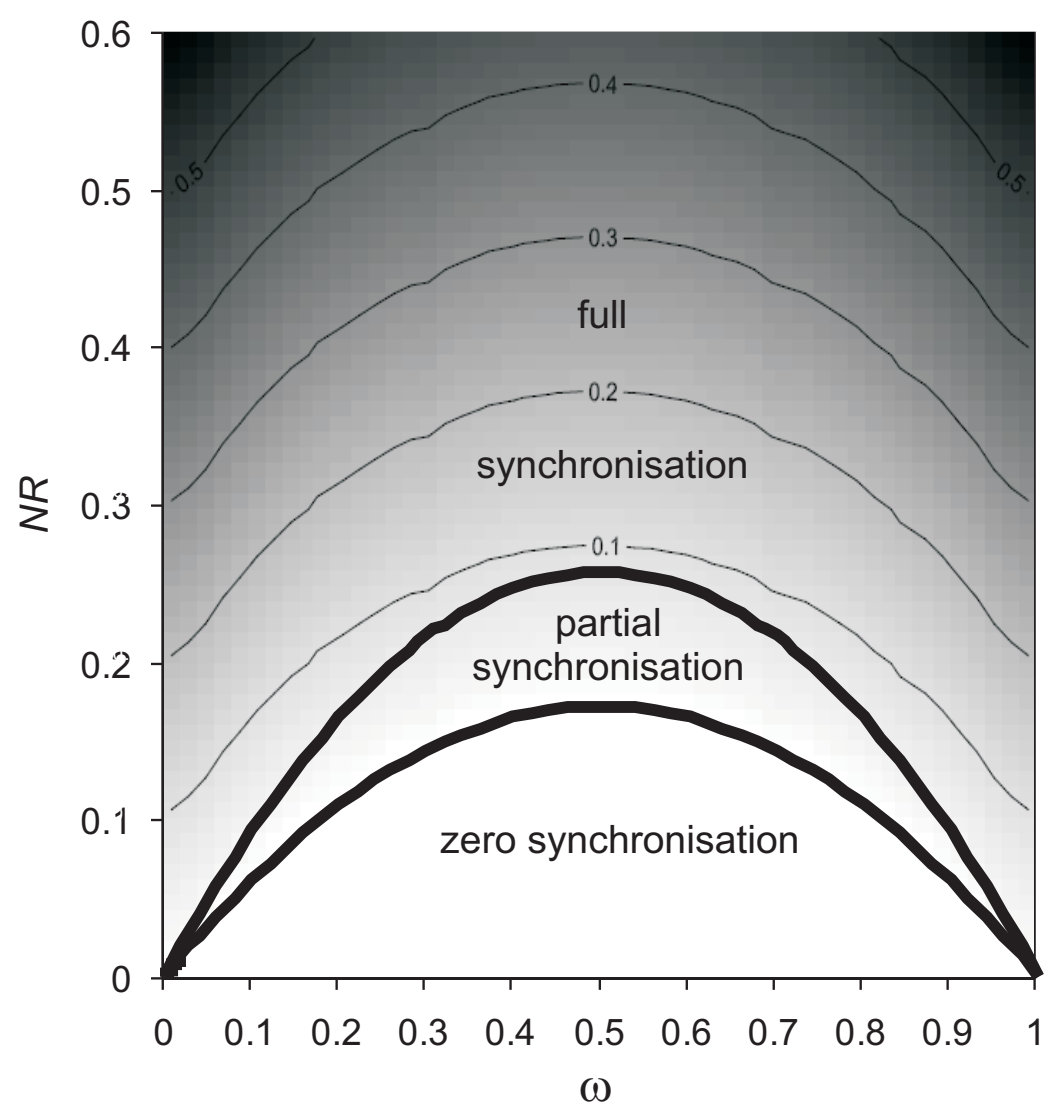




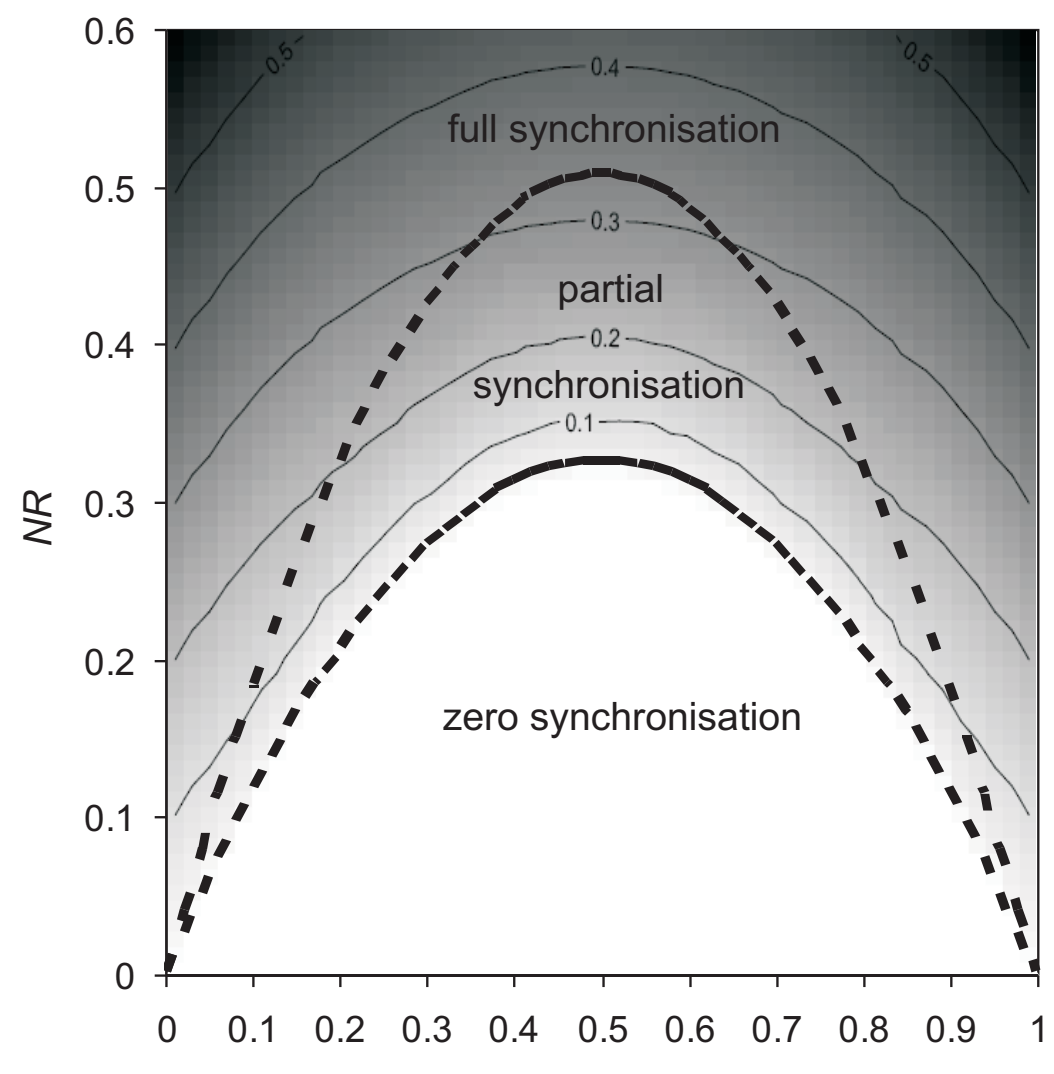

$\omega$ 


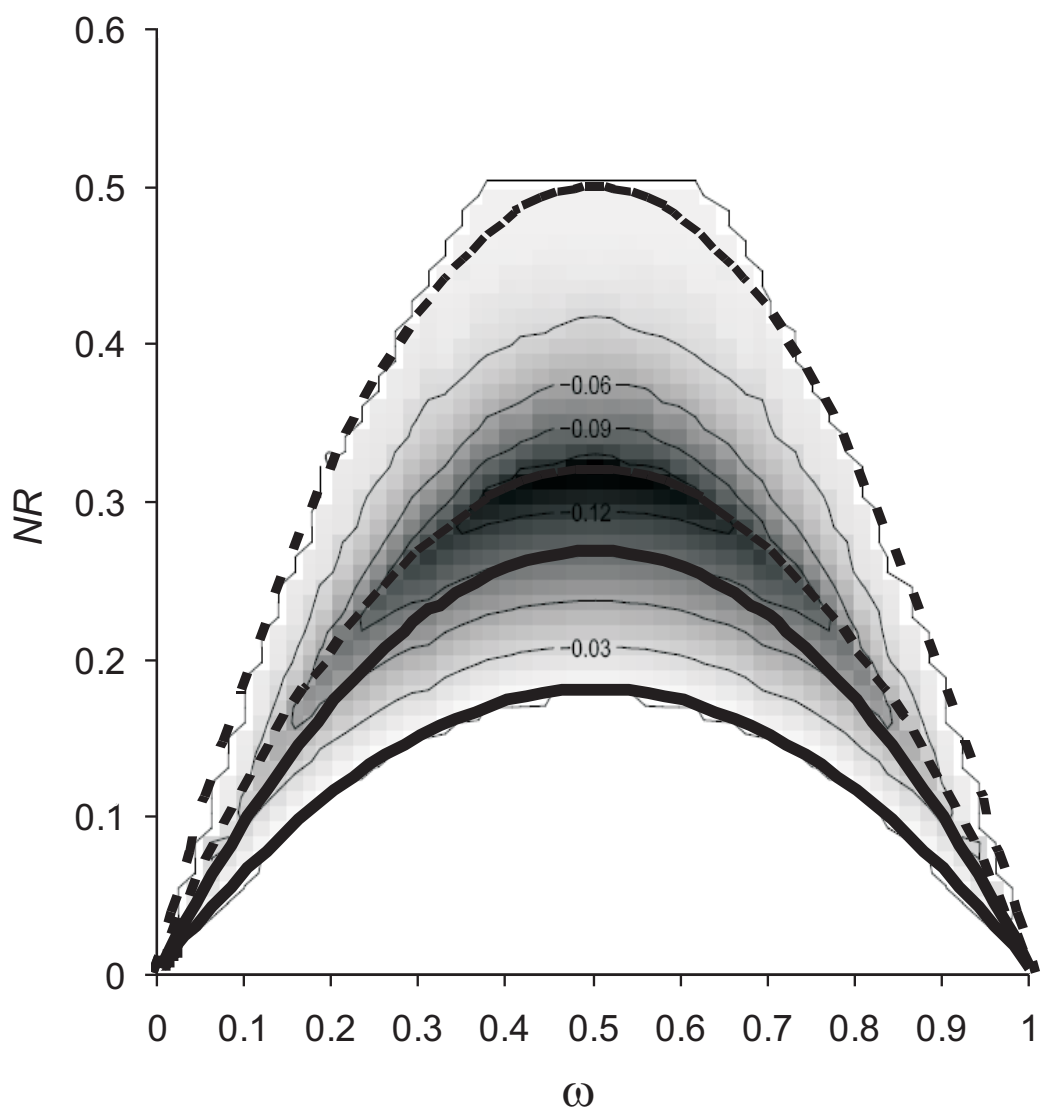


- one departure $-\cdot$ two departures

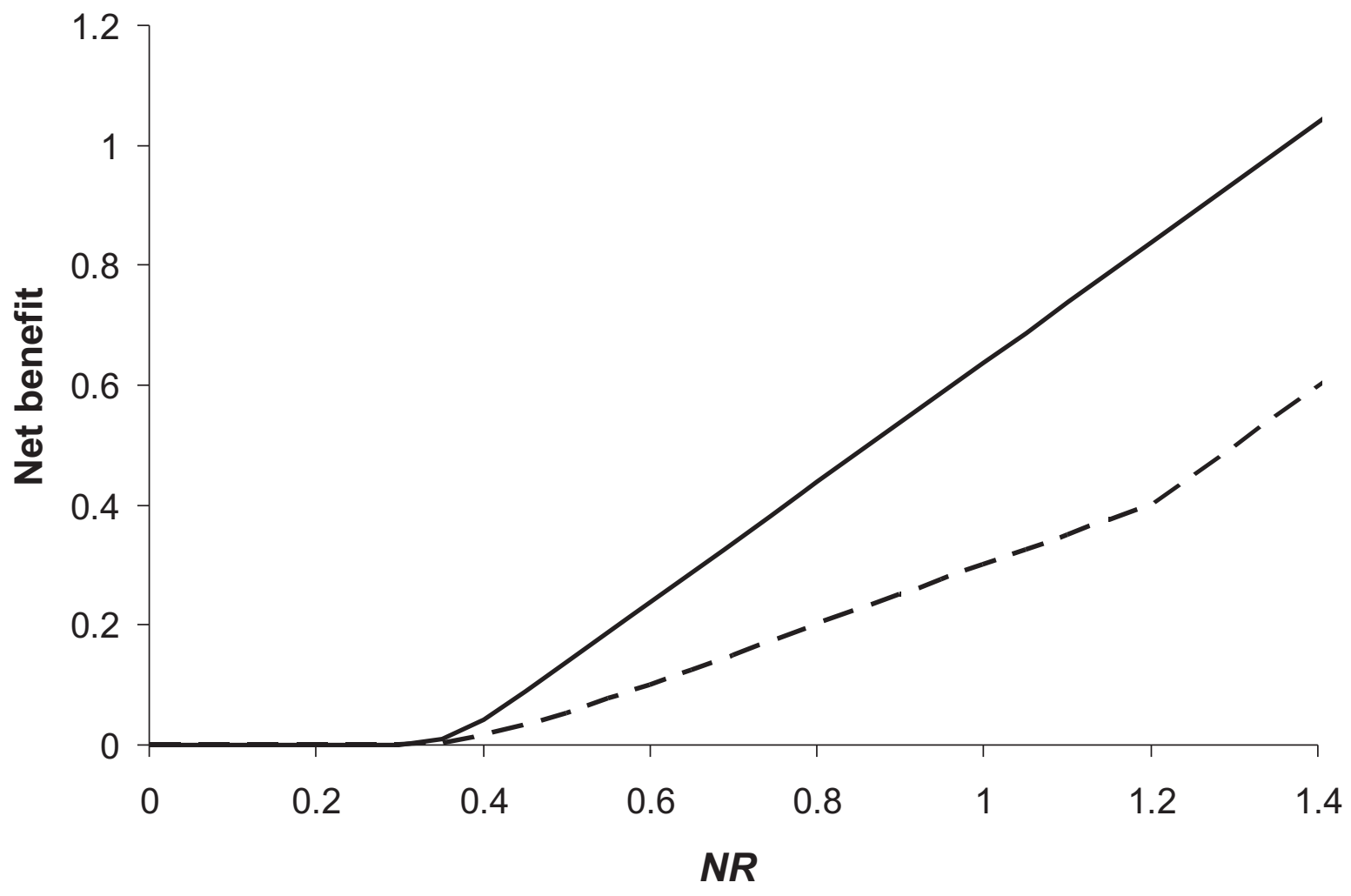


Figure 6

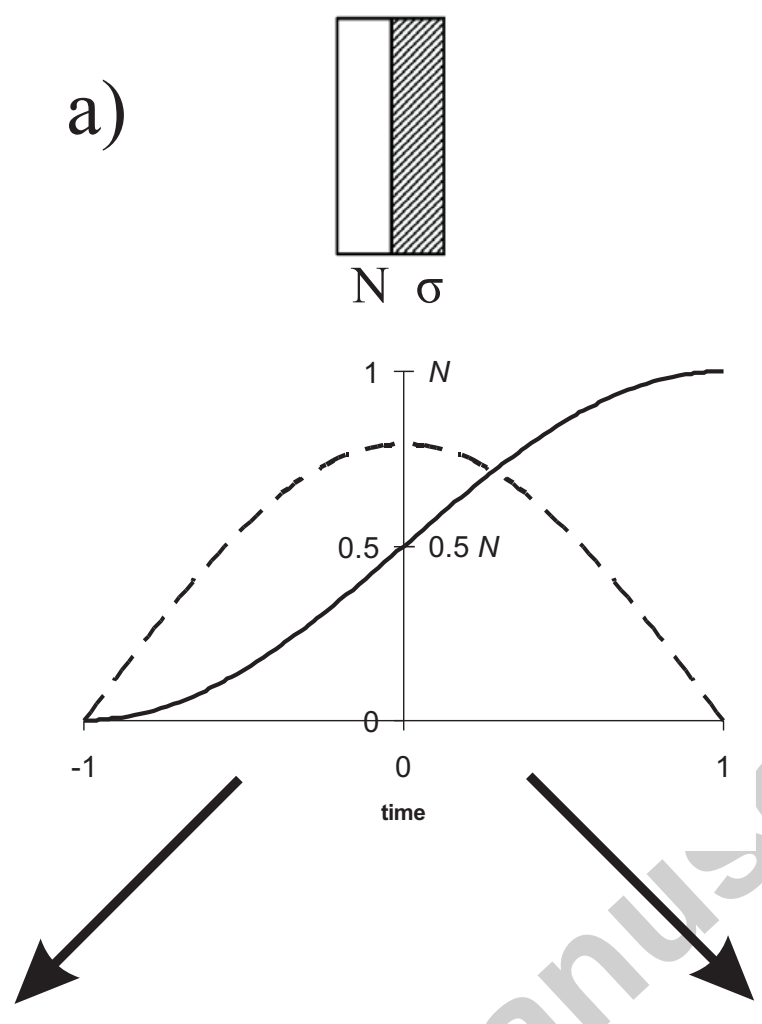

b)

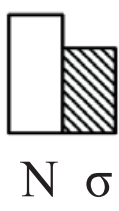

c)
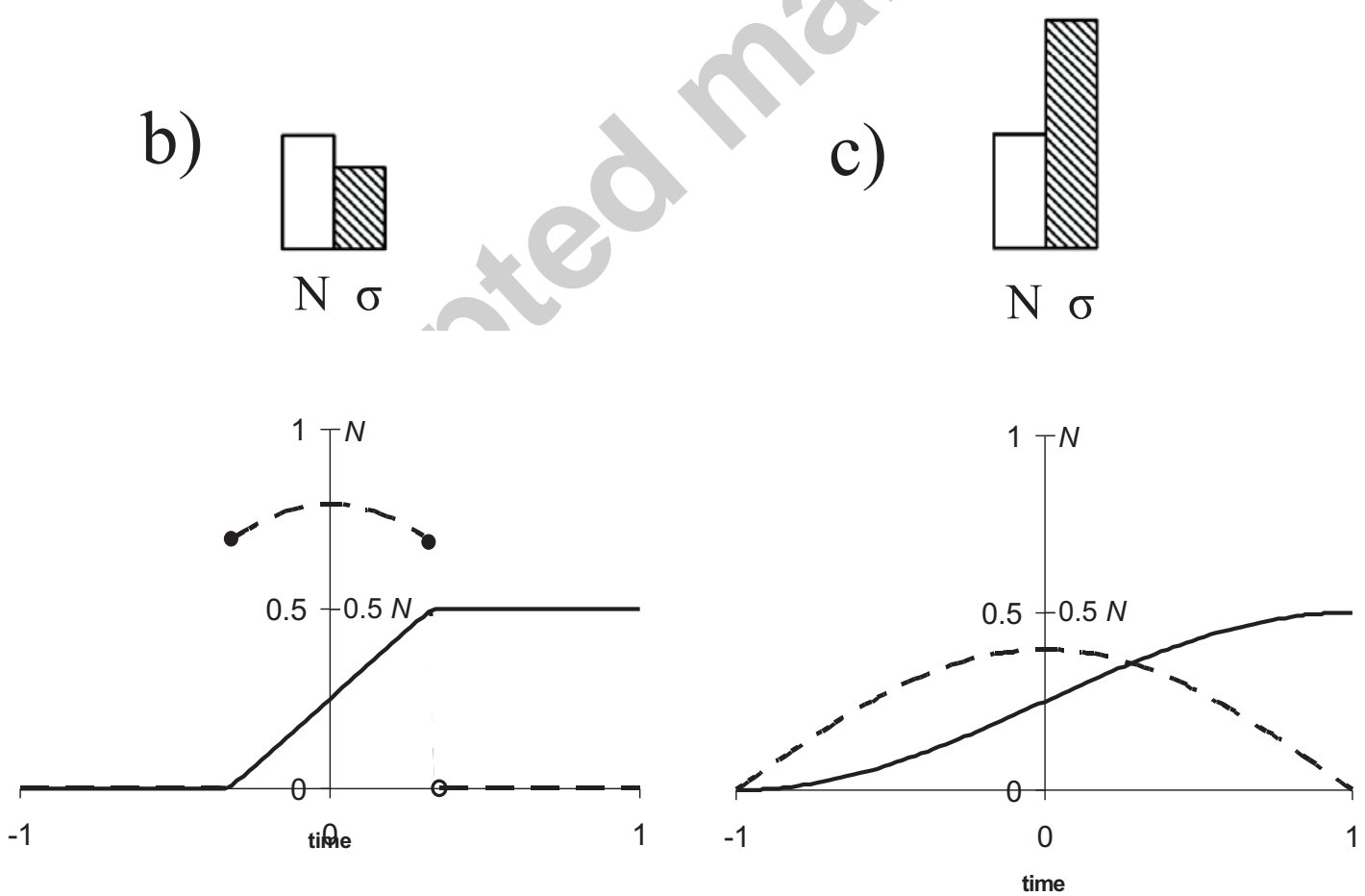
Figure 7

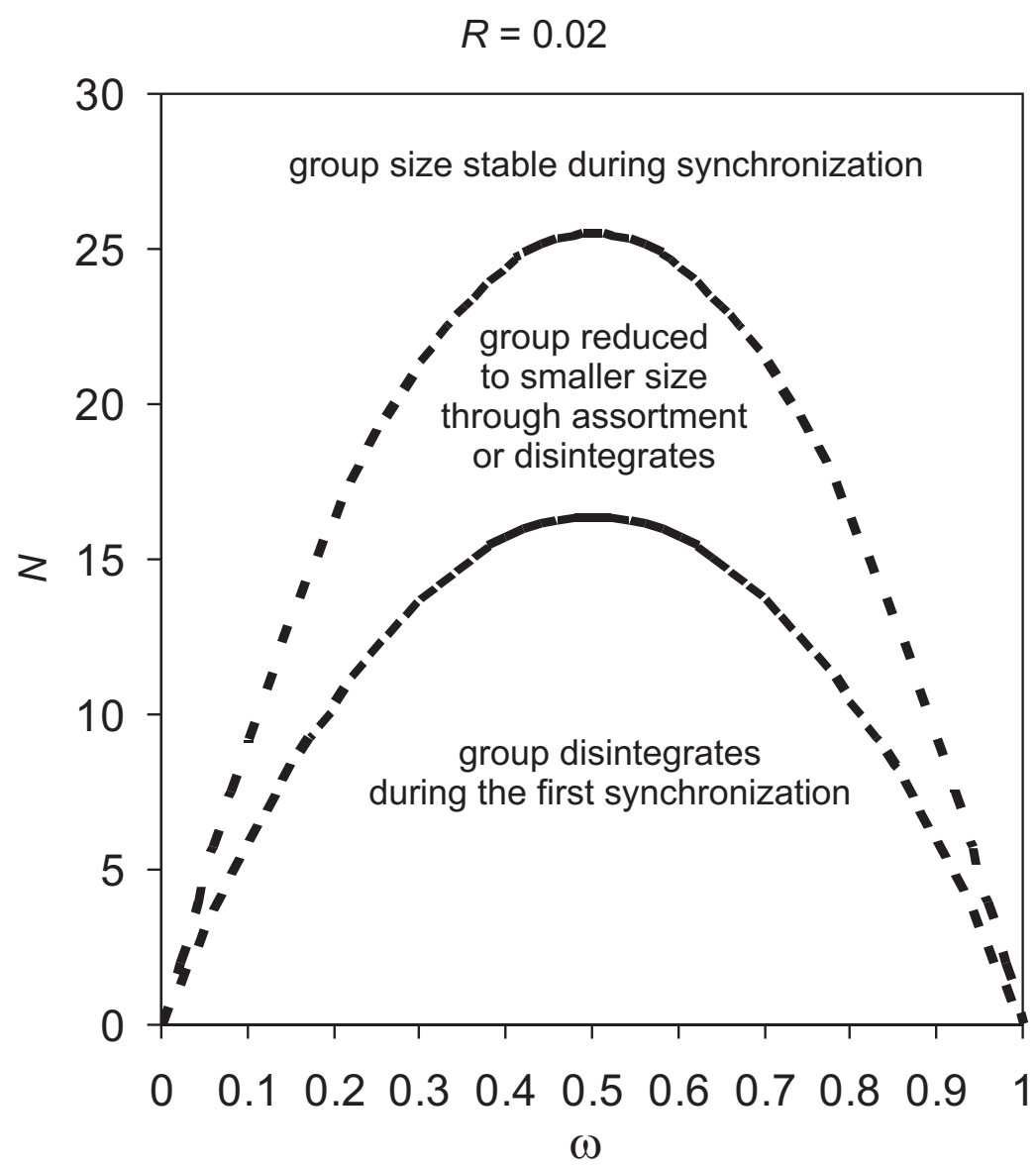


Figure 8
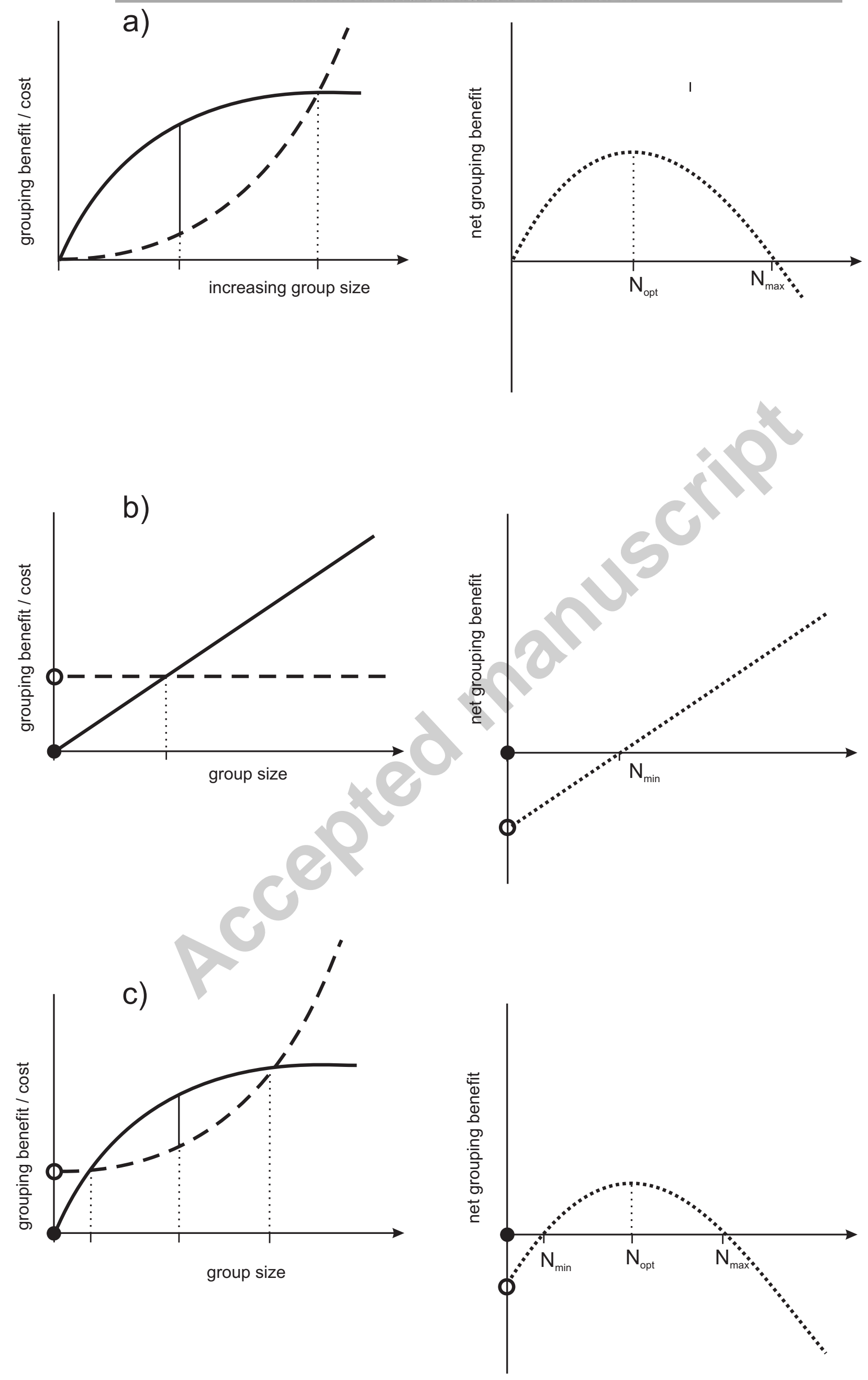